\title{
The feasibility of the actual combat application of the traditional martial arts techniques in modern combat challenge
}

\author{
Xue Shifa \\ Hai Nan Hainan College of Economics and Business 571127
}

\begin{abstract}
The traditional Chinese martial arts are the pride of the Chinese national specialties, but with the development of the western modern combat, some traditional martial arts bias appeared, such as the argument of the real fight of the traditional martial arts. This paper starts from the traditional historical origin, and analyzes the actual combat possibility of traditional martial arts to study the feasibility of the actual combat application of the traditional martial arts techniques in modern combat challenge.
\end{abstract}

Key words- the traditional martial arts techniques; modern fight; challenge in actual combat; the feasibility

\section{INTRODUCTION}

Chinese traditional martial arts are a system of containing martial arts and morality,it is also the pride of the Chinese national treasure. Especially under the spread of Hong Kong actor and martial arts master Bruce Lee, the power of film and television works makes Chinese Wushu known to the world, Chinese Kung $\mathrm{Fu}$ has become a distinctive cultural label in China. But the argument on the actual combat of the traditional Chinese martial arts has not been stopped, some people think that the Chinese Kung Fu has been deified, they think martial arts are a hollow, namely the accusers, it has no actual combat ability and it is is very "soft" compared with the international well-known integrated combat and Muay Thai. And the boast of Shaolin and Wudang is the film and television propaganda, the most direct reason of this view is: China's candidate had not gained the grade in any international combat games so far, such as K1, UFC, MMA. While another point of view is Chinese Kung Fu is invincible, this view largely contains a nationalist sentiment, because any Kung Fu may not be invincible. Then if the traditional Chinese Kung Fu actually has the actual combat, if the martial arts techniques are feasible in modern challenge, this paper will answer it.

\section{The origin of traditional Chinese martial} arts

Martial arts fundamentally regard attacking as the main content, and regard the fight as the main form. It originated from the ancient ancestor's production labor, people gradually accumulated the fighting skills and defensive skills in the process of hunting, this is the foundation of the offensive and defensive skills in martial arts, so the period of primitive society is a burgeoning stage of the martial arts. It often happened the conflict war between the tribe in the clan commune period, this brought the actual experience for the fight. The Tai Chi theory provides a theoretical basis for the Chinese martial arts in the Chow period, and it began to form a standard system. The martial arts also ushered in the golden period of development in the feudal society. The wrestling, fencing and the sword dance prevailed in the Qin and Han dynasties. For example, "the latest sword dance" in the allusions of Hongmen Banquet explains the basic features of martial arts at that time. Wu Zetian began to introduce the Wu Ju system in the Tang dynasty period,it has played a great role in promoting the development of the martial arts. Some of the folk martial arts organizations began to emerge in the Song and Yuan period, and the folk Kungfu activity began to flourish. The peak of 
the martial arts is in the Ming and Qing dynasties, the Chinese martial arts schools appeared. Chinese martial arts have become a part of the sport in modern times, even China Wushu team also participated in the Berlin Olympic Games show in 1936. The traditional Chinese martial arts have been booming in modern times.

\section{The actual combat characteristics of the Chinese traditional martial arts}

There is no denying the fact that the traditional martial arts are mixed with the ceremony symbolic action on the offensive and defensive skills. The traditional martial arts still followed the low efficiency practice on the achievement method, so some of the arguments think the traditional martial arts practice is not to combat and compete, but to practice. However, this opinion seems to be biased, because any kinds of martial arts must be with the combat function first. But as the end of the cold steel era, the traditional Chinese Wushu combat function is inevitably weakened. And Chinese martial arts evolved various mysterious complex schools in the historical evolution, many martial artists put their mind on the difference between other genres, so the symbolic sign movement has a lot and the performance characteristic is more intense. But these actions are useless for the actual combat, for such discussions actually come from a famous battle for life and death.

$\mathrm{Wu}$ style Tai Chi master Wu Jianquan's eldest son Wu Gongyi and Baihe school Chen Kefu had a life and death war in Macao in 1953, and they also signed the life and death contract. Due to the Hong Kong law is rigorous to the duel at that time, finally the two sides came to Macao, the two Wulin fight became the biggest news at that time. Perhaps many people's imagination about the Wulin duel is the hand is like the high winds, and they are as quick as the lightning, but the fact is not. Because this match left a video, this has been regarded as the earliest Chinese Wushu combat video. But the video has become the butt of jokes to some actual combat fighters, most comments are "like two child's play". The influence of the video broke many people's imagination for the Chinese traditional martial arts. When people debate the Wushu combat, it can make many traditional martial arts amateurs speechless.

The duel seems to confirm the point of view of the lack of actual combat in the traditional martial arts, and so this is really true, of course, the answer is no. First of all, the traditional martial arts have played a decisive role on the civilian self-defense or the application of the battlefield from the historical point of view, this is undeniable. Second, the traditional martial arts still embodies the effect in the modern society, such as the martial arts coach of the people's liberation army (PLA) of the People's Republic of China Fan Yinglian studied the Shaolin school, the armed police martial arts coach, the central force coach and the bodyguard of the central top leader Cheng Lixian practices Shaolin school and Bagua. The combat compulsory content is the traditional martial arts in Chinese special forces, even it is also one of the combat compulsory contents in the United States coast guard and part of special forces, it also contains the traditional Chinese martial art of Wing Chun. These examples explain there is an actual combat in the traditional Chinese martial arts which are developed after one thousand fights, so it is completely wrong and not confident to look down on the China's traditional martial arts.

\section{The difference between the actual combat challenge and life practice challenge}

There are many "tips" in the practice of traditional Chinese martial arts, because the ancient martial arts experts paid attention to use one move to win the enemy. And most of the martial arts are more pay attention to cultivating their morality, they think martial arts are the internal check and stopping the violence, that is to practice martial arts are to repair their inner cowardice and fix the outside violence. Most of the traditional martial arts practitioners don't like to "fight", although it is the martial arts practice. This kind of training is the practice of 
body and mind and the physical fitness, it is not regarded as a good method to harsh, so the traditional Chinese martial arts pay attention to "avoiding the wars", it is a deterrent force, which declares to the world: I am a practitioners, don't mess with me. So they never take the initiative to fight, it has the substaintial distinction with the competitive challenge of the actual combat. And it doesn't work for some Chinese traditional martial arts skills on the ring. The strength and speed are the most important in the martial arts fighting, this is also the basic skill of all the fighting. For example, if one party's strength and speed are not as good as the other party in the actual combat life, then he will not recklessly approach, but think some "tips", such as attacking the other's waist and neck that are not easy to defense. Or they will not take the initiative to attack, but when the other attacks, they begin to attack on the key part. These techniques are a form of good fighting skill in the eyes of the Chinese traditional martial arts practitioners, but these actions are almost foul in the challenge of actual combat. Such as there are such regulations in the MMA. So this is one of the reasons that the traditional Chinese martial arts can't board the international competitions.

To sum up, there is a fundamental difference between the Chinese traditional martial arts combat and the ring actual combat, they have a different style in the real purpose and actual combat ways.

\section{The feasibility of the traditional martial arts techniques used in modern ring fight}

The most typical technique is "down" in the traditional martial arts. It is the so-called with static braking method, it pays attention to twisting the waist, twisting the body, standing up, thrusting against the ground to make the opponent lose the balance and fall on the ground in the actual combat, and in the traditional martial arts and sweep the leg, and these techniques are still able to be used in the challenge of actual combat.

First, the Kung Fu pays attention to fast. The speed is the key factor that decides the outcome of the combat in the Wushu combat, modern challenge fight, of course, has no exception. The research data show that the fastest reaction time of people is 0.2 seconds, and a lot of fighters are faster than this time, so how to decipher the superfast response speed is very important. There is an idea of the unity in the waist and the horse in the traditional martial arts in China, that is to say we should try to use the waist strength in the fight, and we can determine it ahead of time by observing the opponent's body changes, especially the shoulders and pace. It can not only break the opponent's punches offensive, but also find the other's weaknesses.

Second, Kung Fu pays attention to the hardness. The good intensity of resistance to attack is also one of the important abilities to win the game in modern challenge of actual combat, a player is injured because of the attack, the other side can win with the absolute advantage. This kind of situation is common in the ring game, so we can learn intensity of resistance to attack is very important. This ability can only be gotten through the long-term training. The octupole punch on the pile and the Yong Chun Quan train the intensity of resistance to attack in the traditional Chinese martial arts. The learning of these techniques can train practitioners combat ability, and it is very be necessary for the challenge of actual combat.

Third, the Kung Fu pays attention to the force. "Force" here is mainly the striking ability, because if the punch strength of one party is not enough to bring down the opponent in the challenge, then he may lose half. So the players must have the initiative, this is the main winning means of modern fight. Because the best defense is the offense, and the Chen Tai Ji Tuishou is considered to effectively improve a joint muscle coordination strengthen the power and the startup speed, and it can also improve the ability of controlling the body movements in the traditional martial arts, the physical respondance ability and the attack power are fairly effective in the challenge of actual combat. 


\section{Conclusion}

This paper regards it is feasible to apply the traditional martial arts techniques to the challenge of actual combat. Because no matter in terms of the actual combat of traditional martial arts, or some ways to exercise, it is effective to improve the ability to fight. But some of the misunderstanding and the abnormal idea to the traditional martial arts make the traditional martial arts not attract the attention of modern martial arts training. So it requires the traditional martial arts practitioners put down the unrealistic fantasy and go into the reality to truly find the real combat meaning of the martial arts.

\section{References}

[1] Tie wenyi. Wushu free combat competition system characteristics research [J]. Journal of Shanghai Sports Institute, 2013,04.

[2] $\mathrm{Hu}$ Hongsen. The traditional martial arts "unify single practice and pair exercise" competition mode study[J]. Journal of Beijing Sports University, 2014,02. 